\title{
Educational Network Projects as Form of E-Learning
}

\author{
https://doi.org/10.3991/ijac.v12i1.9465 \\ Yousef Ibrahim Daradkeh $(\varpi)$ \\ Prince Sattam bin Abdulaziz University, College of Engineering, Department of Computer \\ Engineering and Networks, Wadi Addawasir, 11991, KSA \\ daradkehy@yahoo.ca \\ V.A. Testov \\ Vologda State University, Vologda, Russia \\ O.B. Golubev \\ Vologda State University, Vologda, Russia
}

\begin{abstract}
Great hopes in improving the quality of education, bringing it into line with the needs of society are placed on electronic networking technologies. Such technologies provide great opportunities in the organization of joint activities of teachers and students, individualization of the educational process, the transformation of learning into self-learning and self-education. At the same time, the practice of introducing e-learning has shown that this system of training raises a number of new problems. In the scientific literature scientists give different opinions on the use of digital technologies in the educational process, and both the positive and negative sides of e-learning are noted. In e-learning, one of the main problems is the understanding of the studied material, and one of the greatest frustrations regarding this problem is the insufficient volume of collaborative creative work of students with a teacher.

To solve this problem, we need a fundamentally new methodological basis of education, it is necessary to radically update the goals, content, forms, methods and means of education, taking into account the flow of information and communication processes in which modern youth grows. Synergetics is considered as a new methodological basis in the article.

One of the types of electronic technologies that allows for the organization of joint creative work of students with a teacher and collective teaching, as well as various forms of control, is the method of projects. The main purpose of the study was to develop a methodology for the application of the project method, designed to prepare graduates not only to work competently with information and work in a team, but also to deeply understand the training material. The subject of the study is the learning process using the project method aimed at understanding the material under study. The article describes in detail the features of the use of the method of projects in the educational process. Design technology involves reliance on the principles, norms and rules of design, the totality that allows you to organize the activities of the student from idea to practical implementation.

Educational network project is one of the activities in the use of Internet technologies. On the basis of synergetic methodology, the article describes the principles of using training network projects. A distinctive feature of the use of
\end{abstract}


educational network projects is the requirement of training in cooperation and collaboration. Particular attention in the learning process should be paid to Web 2.0 services and cloud technologies. Results of a pedagogical experiment on application of network projects in training of students are given. On this basis, it is concluded that network technologies using the project method open up fundamentally new opportunities for the education system to accelerate the individual development of each student and to achieve understanding of the studied material.

Keywords- e-learning, digital technologies, project method, Internet projects, educational training network projects, portfolio, web 2.0 services, cloud technologies, interactive classes, collaborative learning.

\section{Introduction}

Open Education of the XXI century is quite closely connected with the development of electronic technologies, on which are laid great hopes for improving the quality of education, bringing it into line with the needs of society. Currently, the pedagogical community is actively discussing the need to develop new educational technologies based on the use of the Internet and local networks that can provide a leap in the development of education. Such technologies should allow solving a number of problems facing modern schools and higher education institutions. Network technologies offer completely new opportunities for creativity and self-realization for both students and teachers. The Internet opens up new opportunities for participation in professional scientific communities, it expands not only our thinking abilities, but also the field of joint activities and cooperation with other people. A distinctive feature of education in the modern information society is the requirement of learning in cooperation and collaboration, through the construction of knowledge and mutual exchange of views with other students and teachers on the way to achieving a common goal.

As a result of the intensive expansion of digital technologies, the conditions for education have changed radically. A person has considerable additional opportunities to realize his own intellectual potential. Digital technologies have a profound impact on the human person, but the various aspects of these influences have not yet been studied sufficiently. Young people are developing in a dynamic information environment as they quickly master new communication and information tools and technologies. However, most students consider these tools and technologies only as tools of communication, entertainment, and relaxation. The psychological sphere of the "generation of numbers" is changing: the way of thinking of today's schoolchildren and students due to their constant communication in the network with the mass media becomes figuratively emotional and tends less to abstract constructions; fragmentaryfigurative thinking becomes predominant. The integrity of knowledge is broken, some fragments of information obtained without much mental effort from the Internet do not teach students to work, but rather create the illusion of simplicity in obtaining new 
knowledge. All of this goes against the conventional style and the existing methods of developing educational material.

According to the observations by psychologists and teachers, representatives of the digital generation reduce their own cognitive activity, as well as reduce the amount of working memory. Their mind is characterized by fragmentary and haphazard knowledge: lack of clear ideas about the boundaries of their own knowledge, inability to distinguish between significant and secondary information, fixing attention on the external sides of the problem, a lack of need to understand the material presented, etc. [1].

A significant part of the pedagogical community was not ready to take advantage of the wide use of network technologies in the educational process, and to take into account the negative phenomena associated with total computerization. The reasons for these negative phenomena originally seemed in the shortcomings of methodical approaches used in the implementation of such technologies in training. Later it became clear that a fundamentally new methodological basis of education was needed, it is necessary to radically update the goals, content, forms, methods and means of education, taking into account the flow of information and communication processes in which modern youth grows. [2], [3.]

In teaching practice, the most common use of ICT is as an aid to learning, making the learning process more effective, and eliminating its routine elements. But to the extent to which this increases the effectiveness of training, there is no objective assessment.

\section{$2 \quad$ Literature Review}

Although digital technologies have been introduced in developed countries for a long time, the conclusions and recommendations of experts are very controversial. The ardent apologists of the introduction of digital technologies in education, for the most part, state unfairly that in a digital society the loss of abilities in traditional fundamental education may be not negative, but a positive trend in the development of the brain. In their opinion, these negative phenomena in the development of the brain are only from the point of view of traditional pedagogical science. They feel that the traditional subject system knowledge that we are used to in schools and Universities is something the new generation does not need, that they only clog our memory and block the true creative abilities of a person [4].

However, many specialist publications are more critical. Scientists from around the world have conducted a large number of studies on the impact of network technologies on the brains of schoolchildren and students. These results are summarized in a book by the German neuroscientist and psychiatrist Manfred Shriner. This scientist convincingly proves that digital technologies are good only for those who have a good educational training, for them digital technologies are a tool for obtaining and developing new knowledge. However, children who have not yet fully developed brains can be adversely affected. Learning always involves your own mental work: the more active and deeper the brain processes the information, the better it will be understood. 
Computers do mental work instead of people and therefore they are not suitable for training. The use of networks and computers in education leads to the formation of children's superficial thinking [5].

For these reasons, in those countries where the mass introduction of digital technology began earlier, in elite schools, as well as in families with a high level of education we see a limitation of the communication children have with various gadgets and even the prohibiting the use of them up to a certain age.

Currently, the society is interested in specialists who are able to act independently, actively make decisions, and quickly adapt to changing living conditions. Therefore, there is the task of training graduates who are able to competently work with information (collect facts, analyze, summarize them, put forward hypotheses, suggest ways to solve the problem, compare with similar or alternative solutions, etc.), and at the same time have the communication skills that allow them to work as part of a team. It is possible to solve the task with a thought-out, scientifically based use of new educational and information technologies [6], [7], [8].

At present, two types of computer programs are mainly used in education. The first type includes training computer programs, involving the receipt of portions of information (text, graphics, video) in a certain sequence that provide control over the assimilation at the points of the training course, defined by the teacher. These mainly use multimedia capabilities of the computer in order to fill the lesson with illustrations to make it more entertaining and intense. The second type are training simulation facilities. These systems include both applications and programs that allow the students, possibly with help of a teacher, to create, design computer graphic models, and test educational products that accelerate and individualize the process of determining the level and quality of students' competencies. Existing teaching web-resources in mathematics are, as a rule, a list of unrelated definitions of concepts and problems with solutions. The task of the teacher is to create a technology of mathematical knowledge management on the system basis of ontologies, allowing the process of mastering mathematics to focus on understanding, and to make it more meaningful ([9] - [13]).

One of these technologies is based on the project method. A number of studies are devoted to this technology with the use of information and communication tools, the results allow us to consider this technology very promising. The Internet project is an active and effective method of forming the culture of students in all its diverse aspects relevant to human activity in the modern dynamic society. The analysis of the experience of organization of such projects in various disciplines is carried out in the works [14] - [19].

Currently, the use of Agile technologies is becoming popular in education. At its core, Agile is innovation based on several principles that actually coincide with the principles of synergetics. Students cope with emerging problems through the work they do in self-organized and motivated teams that are able to adapt and respond to changes [20], [21], [22]. 


\section{Purpose and Subject of the Study}

There is no doubt that in the transition to digital technologies the pedagogical community first of all needs to have a sufficiently reliable scientific base. Electronic technologies in education have a number of well-known positive features of use. However, the practice of e-learning has shown that such training has shortcomings, some of which are long-term and fundamental. With the greatest difficulties, e-learning is introduced into the teaching of subjects in which an important role is played by logical thinking and a large degree of abstraction, we see this in the teaching of mathematics for example. To achieve understanding it is necessary to reach unity in several basic parameters: identification of essential properties of the object, the establishment of significant relationships within the object and outside it, and the construction of the integrity of the object under study. To do this in a digital learning is not easy.

Perception should not be reduced only to visual perception of information, it is also necessary to use both auditory and kinesthetic channels. This is very important for gaining understanding is the stage of reproduction. Many students achieve understanding only after they have spoken the training material. This can explain the long-noticed trend of teachers effectively working in pairs. With network training working in pairs can be organized with the help of web-cameras. The use of new information technologies alone does not yet make education effective. It is necessary to make a lot of efforts to develop fundamentally new methods, techniques and means of educational activities in the network space.

The main purpose of the study was to develop methods of the application of the project method, designed to prepare graduates who are able not only to work competently with information and able to work in a team, but also deeply understand the training material.

The subject of the study was the learning process using the project method aimed at understanding the material under study. In order to achieve understanding, it is necessary to reveal the features of content construction and application of the method of projects in the educational process. Design technology should be based on the principles, norms and rules of design, and the totality which allows you to organize the activities of the student from the idea to its practical implementation.

\section{$4 \quad$ Research Methodology}

Training can be considered effective only when it achieves an understanding of the basic concepts and methods. Therefore, in the study we relied on the achievements and methods of psychology. According to psychologists, understanding occurs when there is active learning. E-learning is often a replacement for teacher dialogue and the passive perception of student's presentations, video and slide lectures. In teaching, the speaker always translates his thought from the internal, semantic language into the natural language, and the listener (reader) from the natural language into the semantic language. From this point of view, each person thinks in his own language. In e- 
learning, teachers do not communicate with one student or even a group of students, but through a network and electronic textbooks with a large flow of students, and they have to keep in mind a completely average "language of thinking."

For the focus of learning understanding the dialogue is necessary, but for its occurrence you need a certain organization of educational material, taking into account the specifics of the subject. It was assumed that e-education creates all conditions for improving the quality of education. However, the practice of e-learning has shown that in this system of training there is a number of new problems arising from the lack of joint creative work of students with the teacher. Such joint creative work is possible only in dialogue with the teacher, or with other students. In principle, such a dialogue can be organized in electronic educational materials on any subject, including mathematics. However, it remains the most difficult to take into account in these materials the individual cognitive style of each student and his interests. So far, electronic means in this regard can not compete with the teacher.

In the new information environment, the teacher remains the most important link in the learning process. Based on the study of information related to the effectiveness of teachers, researchers found that large differences in learning outcomes are primarily due to the quality of teachers' work, and not the use of new electronic technology [23].

Therefore, the main focus of the study was on the development of such methods of application of electronic network technologies that provide great opportunities in the organization of joint activities of teachers and students, such as: individualization of the educational process, the transformation of learning into self-learning and selfeducation, and allowing the organization of interactive classes and collective teaching, as well as various forms of control. All this led us to the need to use the synergetic methodology [3], [24], [25].

One of the principles of synergetics is the principle of coherence. One of the manifestations of this principle in teaching is collaborative technologies. Collaborative learning is an approach to learning in which students work together in a group, solving common learning tasks to achieve a common educational goal. Collaborative technologies allow the organization of training in the process of joint solution educational tasks, carrying out mutual knowledge exchange. Participants of the process gain knowledge through active joint information search, and through discussion and understanding. In the case of collaborative learning, knowledge comes from the combined efforts of both the group members and the teacher. Collaborative learning certainly includes the use of educational network projects. Cooperation between students in the course of a joint project increases their motivation and thus provides the best conditions for achieving the set learning goals. 


\section{$5 \quad$ Results of Observations and Discussions}

When developing the technology of using the project method using computer networks, we relied on the principles of synergetics as well as the principles, norms and rules of project activities.

The first of these is the principle of integrity, which is to create a unity of pedagogical conditions for the implementation of educational projects, the relationship between the purpose of the project, its content and means to achieve the goal, as well as continuity between the stages of the project. The integrity of the content is achieved if the work begins with the identification of the essential properties of the object under study. The location of the studied material should be such that all subsequent flows from the previous. When choosing the means of achieving the goal, it is important to create conditions for the manifestation of each student's cognitive and creative activity through the use of modern electronic means and personal capabilities that trigger the mechanisms of self-education. Rigid management of project activities are ineffective.

The second principle, the principle of activity and independence, is a purposeful active perception and research of the studied phenomena, their understanding, creative processing and application. Projects should provide an opportunity for personal development, self-control and self-realization. In this case, an important part of the design is the transformation of the subject of design. Performing independent work, students actively operate with the acquired knowledge, abilities and skills, and make search activity that strengthens their cognitive activity.

The third principle is the principle of applied orientation of training, the implementation of which is associated with the development of the system of personality qualities of the future specialist in the process of training, ensuring the performance of functions are adequate to the needs of certain practical activities.

Each project should be based on a problem. The problem of the project determines the motive of activities aimed at its solution. The choice of the problem is the most difficult and important point. It should be understood that the problem should always be based on a contradiction. Finding a solution to the problem becomes the goal of project activities. Important moments in understanding the importance and scope and level of unsolved problems, includes the study of the state of the issue, and the analysis of scientific literature on the project.

A necessary component of the project is reflection. It should be held twice: immediately after the presentation, as this is an acute emotional moment when it is necessary to sum up the first results, and after a while, when there will be a rethinking of the work, emotions will fade away. In the second case, it is necessary to analyze in more detail the advantages and weaknesses of the work, and the possibility of its continuation.

The degree of activity of students and teachers at different stages of the project is different. The degree of activity of students in the educational project depends on the level of formation of their skills and project activities. The role of the teacher is particularly important in the first and last stages of the project.

As our experience shows, network technologies contribute to the convergence of learning and research. Network technologies also open up fundamentally new 
opportunities for accelerated individual development in each student, achieving their understanding of the studied material. Network projects are a convenient tool for joint development of problem solving skills, checking the level of knowledge, as well as the formation of interest in the subject.

The most effective long-term projects are designed to solve a fairly complex problems and require a long period of time. Such projects may involve a series of subprojects that can form a whole program. The duration of such projects can be from a month to a year, or even more. The most effective method of projects is working in combination with the technology, and working in groups of cooperation.

Web 2.0 services are well suited for the establishment of educational networking projects. The fundamental difference between these services is the ability to create Internet content for any user, it is a network software that supports group interaction. These group interactions include participant's personal actions, such as recording thoughts, taking notes and annotating other people's texts, posting multimedia files, and communicating with each other.

The wiki implements a collective hypertext model where the ability to create and edit any record is given to each member of the online community. The wiki can be used for a variety of purposes: both as a means of organizing collaborative work on collective projects of a whole group of students, and as databases - repositories of collective experience.

\section{Results of the Experience}

For two years we conducted a pedagogical experiment. The main purpose of the experiment was to confirm the effectiveness of Internet projects in teaching mathematics. Experimental and control groups of students were formed. In the experimental group, training in mathematics was conducted with the use of network projects and the use of the basic principles of understanding (identification of the essential properties of the object, the establishment of significant links within the object and outside it, and the construction of the integrity of the object under study). Students in the control group studied the course according to the traditional method. The experiment involved 108 subjects.

The experiment resulted in the following distribution (Fig. 1) on the received estimates for the final control work (on a five-point scale). 
The level of achievement

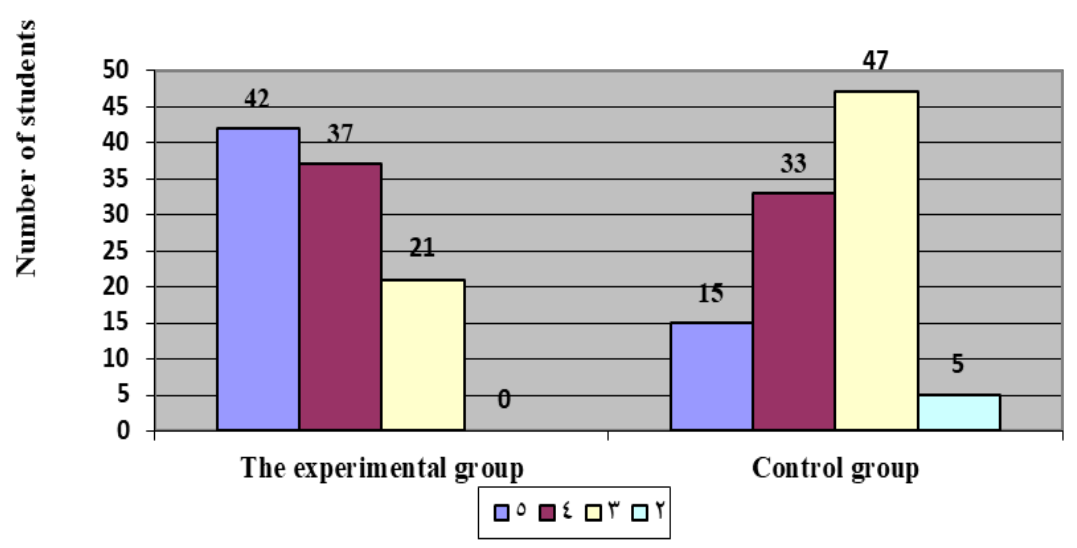

Fig. 1. Level of student achievement

The effectiveness of network projects was also determined by changing the motivation of students to study mathematics through questionnaires, observation, and interviews. The level of understanding of the content of training was checked by means of test tasks and final control works.

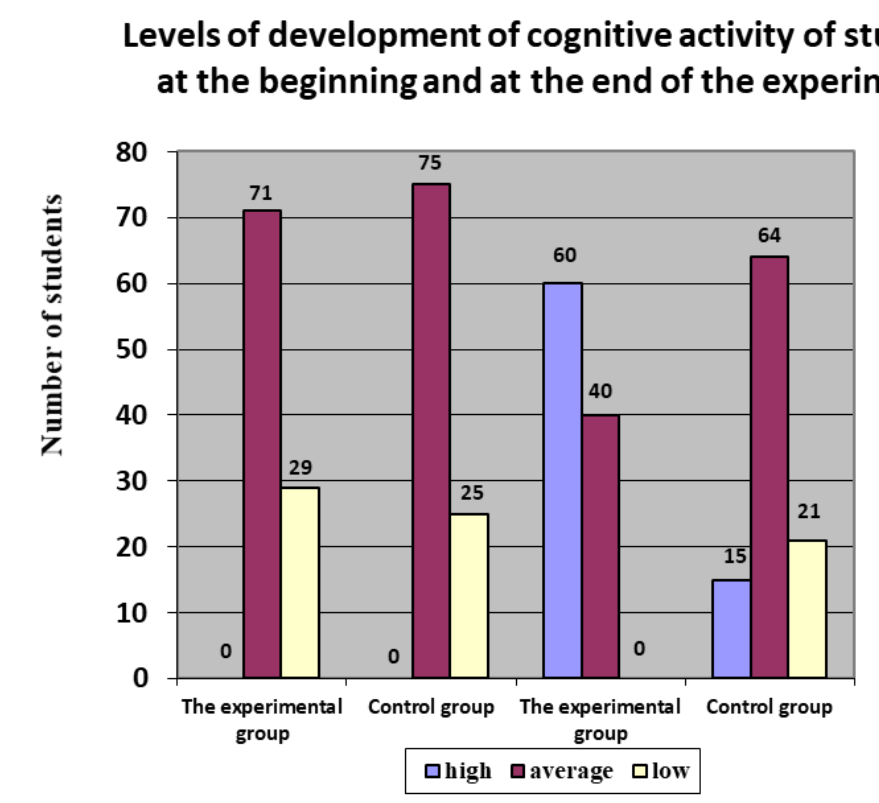

Fig. 2. Levels of development of cognitive activity of students at the beginning and at the end of the experiment 
The following conclusion can be drawn from the survey: the majority of students in the experimental groups have significantly increased their level of cognitive activity.

At the beginning and at the end of the experiment, the levels of the following indicators of cognitive activity were also checked (Fig. 3): the ability to find the right information, the ability to critically analyze the information, and the ability to make decisions quickly.

\section{Indicators of cognitive activity of students at the beginning and at the end of the experiment}

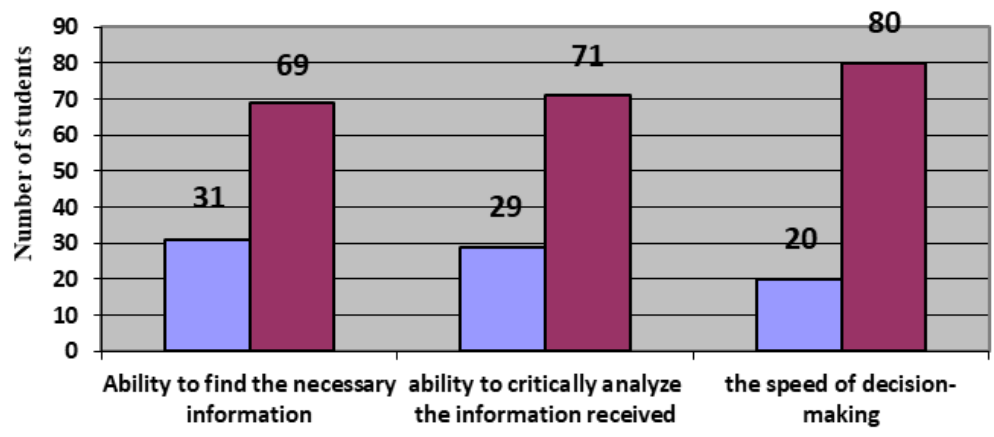

abeginning of the experiment

$\square$ the end of the experiment

Fig. 3. Indicators of cognitive activity of students at the beginning and at the end of the experiment

\section{Conclusion}

In the Vologda state University electronic network technologies are used in teaching mathematics in combination with traditional methods. As shown by the experience and results of the experiment, when using network projects in training, the qualities of the personality of students speak to the high cognitive activity that was developed. In comparison with the beginning of the experiment, such a quality of personality, closely related to the understanding of educational material as "the ability to critically analyze the information received", has also been developed.

Thus, network technologies contribute to the convergence of learning and research, increase cognitive activity of students, and solve the problem of understanding the material under study. 


\section{$8 \quad$ Future Research}

Network technologies using the method of projects open up fundamentally new opportunities for the education system to accelerate the individual development of each student, to achieve maximum activity of the individual in learning and understanding of the studied material. Intensive introduction of electronic network technologies in education is an inevitable process. However, e-learning should not be seen as a substitute for traditional classroom learning, but rather as a harmonious combination of the two. It is necessary for scientists and teachers to develop essentially new manuals, to develop new nonconventional methods, receptions and means of educational activity which would provide the educational effect of a connection between network and traditional technologies in training.

\section{References}

[1] A. Klekovkin, "Problems of education in the open information space", in Education and science. 2014, №. 7. pp. 4-23.

[2] V. A. Testov G, O. B. Golubev, Education in the information society: the transition to a new paradigm. Monograph. Vologda: VoGU, 2016. $176 \mathrm{p}$.

[3] O. B. Golubev, V. A. Testov, "Network Information Technologies as a Basis of New Educational Paradigm", in Procedia - Social and Behavioral Sciences, 2015. Volume 214, pp. 128-134 https://doi.org/10.1016/j.sbspro.2015.11.604

[4] G. A. Klekovkin, "Teaching mathematics in the digital society", in N. Iv. Lobachevsky and mathematical education in Russia. Proceedings of the international forum on mathematical education, October 18-22, 2017. Kazan: Kazan publishing House, 2017. Vol.1. pp. 52-56.

[5] M. Spitzer, Antimoth: digital technology and the brain. Moscow: AST, 2014. 288 p.

[6] V. D. Shadrikov, I. S. Shemet, "Information technology in education: pros and cons", in Higher education in Russia. 2009. №. 11. pp. 61-65.

[7] V. A. Testov, "Mathematical education in the network space", in Education and science, №2, 2013. pp. 111-121.

[8] O. B. Golubev, O.Y. Nikiforov. "Development of the information educational environment of modern higher education”, in Innovative journal Region, 2014. №. 1. pp. 57-61

[9] V.A. Testov, "Electronic technology in the teaching of mathematics: the problem of understanding" //Informatization of education and methods of e-learning materials II international. scientific. Conf. Krasnoyarsk, September 25-28, 2018. Part 2 /Ed M. V. Noskov. -Krasnoyarsk: Sib. Fader. Un, 2018, pp. 285-289.

[10] A. Lalingkar, C. Ramnathan, S. Ramani, "Ontology-based smart learning environment for teaching word problems in mathematics". Lecture Notes in Educational Technology, 2015, pp. 251-258. https://doi.org/10.1007/978-3-662-44188-6 35

[11] D. Tzoumpa, T. Karvounidis, C. Douligeris, "Towards an Ontology Approach in Teaching Geometry". International Conference on Interactive Collaborative Learning. ICL 2016: Interactive Collaborative Learning, pp 198-209. https://doi.org/10.1007/978-3-319-50340$\underline{0 \quad 16}$

[12] D. Tzoumpa, T. Karvounidis, C. Douligeris, "Work in Progress: Extending the Application of Ontologies in the Teaching of Geometry": The Right Triangle in the Circle. 8th IEEE 
Global Engineering Education Conference (EDUCON 2017), pp. 893-899. https://doi.org/10.1109/educon.2017.7942953

[13] L. R. Shakirova, M. V. Falaleeva, "Mastering mathematical knowledge by students using ontologies" / Actual problems of teaching mathematics and Informatics at school and University: proceedings of the IV International scientific conference in two volumes. Vol.1. Moscow, MSPU /ed M.V. Egupova, L.I. Borzenkova. - Kaluga: AKF "Politop", 2018, pp. $258-261$.

[14] Y. T. Los, "Stages of creative design - step to practical skills", in Rural school, 2000. No. 1. pp. 64-67.

[15] A.V. Andreev, S. V. Andreeva, I. B. Dotsenko, "Practice of e-learning using Moodle". Taganrog: Publishing house. TTI YUFU, 2008. $146 \mathrm{p}$.

[16] O. B. Golubev, "Network projects in teaching computer science and mathematics". Monograph. Vologda: VoGU, 2011. 138 p.

[17] O. B. Golubev, O. Y. Nikiforov, T. A. Pavlova, "Profile change "Interneshka", in Narodnoe obrazovanie, 2014. №. 2. pp. 195-199.

[18] O. B. Golubev, O. Y. Nikiforov "Informatization of educational and methodical activity of the University”, in Almanac of modern science and education. Tambov: Gramota, 2012. №. 6 (61). pp. 28-30.

[19] T.V. Nikulina, "Infographics and educational-creative tasks in the educational process" // Remote and virtual learning. - 2017. - №6 (120). pp. 71-75.

[20] Con Mike. "Agile. Project evaluation and planning". Moscow: Alpina Publisher, 2018. 418 p.

[21] E. Stillman, D. Green, "Learning Agile. Values, principles, methodologies". Moscow: Mann, Ivanov and Ferber, 2018, 448 p.

[22] T.G. Sereda, D.A. Platonova, "Technology in mathematics and Informatics". Actual problems of teaching mathematics and Informatics at school and University: proceedings of the IV International scientific conference. Vol.1. Moscow, MSPU, ed M.V. Egupova, L. I. Borzenkova. - Kaluga: AKF "Politop", 2018., pp. 198 -204.

[23] E.O. Ivanova, I.M. Osmyalovskaya, "Prospective educational technology: a didactic aspect" Pedagogy, No. 1, 2017, pp.3-9.

[24] V.A.Testov, N.E. Smirnov, "Networking technologies in education: the transition to the synergetic paradigm". Math forum. Vol. 11. Research on mathematical analysis, differential equations and their applications; YUMI VNC RAS. -Moscow: Russian Academy of Sciences, 2017. (The results of science. South of Russia.), pp. 68-80.

[25] V.A.Testov, O.B. Golubev, N.E. Smirnov, "The synergy of electronic and traditional technologies in teaching mathematics". Scientific and methodical journal "CONTINUUM. Mathematics. Informatics. Education.» Yelets. 2018. Issue № 3, pp. 59-64.

\section{Authors}

Dr.Yousef Daradkeh is Lecture in the Department of Computer Information Systems at the faculty of Information Technology and Systems, the Jordan of University (JU), and has worked of the Intelligent Software Systems Laboratory in the University of Calgary (UC), Canada, in 2007-2009. He has worked as a Post-Doctoral Research Fellow in the Department of Electrical and Computer Engineering.

Article submitted 2018-08-31. Resubmitted 2019-01-27. Final acceptance 2019-02-14. Final version published as submitted by the authors. 